Trinity University

Digital Commons @ Trinity

Psychology Faculty Research

Psychology Department

$9-2017$

\title{
From Efficacy to Global Impact: Lessons Learned About What Not to Do in Translating Our Research to Reach
}

Carolyn Becker

Trinity University, cbecker@trinity.edu

Follow this and additional works at: https://digitalcommons.trinity.edu/psych_faculty

Part of the Psychology Commons

Publication Details

Behavior Therapy

Repository Citation

Becker, C. B. (2017). From efficacy to global impact: Lessons learned about what not to do in translating our research to reach. Behavior Therapy, 48(5), 718-730. doi: 10.1016/j.beth.2016.12.007

This Article is brought to you for free and open access by the Psychology Department at Digital Commons @ Trinity. It has been accepted for inclusion in Psychology Faculty Research by an authorized administrator of Digital Commons@ Trinity. For more information, please contact jcostanz@trinity.edu. 


\title{
From Efficacy to Global Impact: Lessons Learned About What Not to Do in Translating Our Research to Reach
}

\author{
Carolyn B. Becker \\ Trinity University
}

\begin{abstract}
Although members of the Association for Behavioral and Cognitive Therapies have made significant strides toward the collective goals outlined in our mission statement, we routinely acknowledge that our ability to develop empirically supported treatments exceeds our success in improving dissemination and implementation of said interventions. Further, as noted by Kazdin and Blase (2011), even if we succeeded in having every clinician worldwide administer our best treatments with excellent competency, we still would be unsuccessful in markedly impacting the worldwide burden of mental illness because most treatments require intensive labor by expensive providers. To this end, Kazdin and Blase and others call for increased use of alternative strategies. Examples include increased attention toward prevention; use of lower-cost, simplified interventions; task shifting; train-the-trainer models; community participatory research methodology; and identification of novel funding sources. The Body Project is an empirically supported, cognitive dissonance-based prevention intervention that targets body image, a well-established risk factor for eating disorders, negative affect, unhealthy weight control behaviors, smoking behavior, and decreased physical activity. Supported by a global village of researchers, community activists, and organizational partners, the Body Project is currently being implemented in 125 countries. The aim of
\end{abstract}

The author would like to thank the following organizations for their support: Dove and the World Association of Girl Guides and Girl Scouts, the Eating Recovery Center Foundation, Comenzar de Nuevo, Delta Delta Delta Fraternity, National Eating Disorders Association, New York State, Stavros Niarchos Foundation, Tri Delta, and the Succeed Foundation. The author would also like to thank all members of the global Body Project community described in this paper.

Address correspondence to Carolyn Black Becker, Ph.D., Department of Psychology, Trinity University, One Trinity Place, San Antonio, TX 78212-7200; e-mail: cbecker@trinity.edu.

0005-7894/@ 2017 Association for Behavioral and Cognitive Therapies. Published by Elsevier Ltd. All rights reserved. this paper is to share lessons our team has learned in taking a prevention intervention from early testing to widespread implementation and connect these back to broader conversations occurring in our field regarding the importance of scalability and new directions in improving global mental health.

Keywords: eating disorders; prevention; scalability; dissemination and implementation; body dissatisfaction

The MIssion of THE Association for Behavioral and Cognitive Therapies (ABCT) promotes the "advancement of scientific approaches to the understanding and improvement of human functioning through the investigation and application of behavioral, cognitive, and other evidence-based principles to the assessment, prevention, treatment of human problems, and the enhancement of health and well-being" (http://www.abct.org/About/? m=mAbout\&fa= Mission). If ABCT members were polled as to our greatest strengths in delivering on our mission statement, we would likely find significant agreement. For instance, review of the 50th Annual Convention Program indicates that ABCT members have, without a doubt, made remarkable headway in developing efficacious treatments for human problems, including but not limited to depression, anxiety, addictive behaviors/substance use disorders, autism spectrum disorders, pathological eating, and general emotion dysregulation. We have also significantly contributed to the understanding of mechanisms of action underpinning both adaptive and maladaptive human functioning. If we consider where we have been less successful, however, we routinely admit that our ability to develop empirically supported interventions exceeds our skill in fostering delivery of those interventions on a routine basis in clinical practice (see Teachman et al., 2012, for a review); this disparity is commonly referred to as the research-practice or 
scientist-practitioner gap (Kazdin, 2016; Teachman et al., 2012).

Kazdin and colleagues (Kazdin, 2016; Kazdin \& Blase, 2011; Kazdin \& Rabbitt, 2013) have also observed that we collectively need to address another critical gap. They note that our field's emphasis on treatment, particularly one-on-one psychotherapy delivered by expert (i.e., master's or doctoral) providers, creates a treatment-gap-or a discrepancy between those who could benefit from services and those who receive them. More specifically, both within the United States and globally, the number of individuals who suffer from mental illness vastly exceeds the number of expert providers we could ever hope to train in the delivery of empirically supported psychotherapy. Thus, even if we eliminated the research-practice gap, we would still fail to address the global burden of mental illness. For instance, within the resource-rich United States we have approximately 700,000 providers to treat an estimated 80 million with mental illness (Kazdin, 2016; Kazdin \& Blase, 2011). Although these numbers are problematic on their own, providers are disproportionately distributed in affluent urban locations, including cities with large universities (Kazdin, 2016; Kazdin \& Blase, 2011). Yet many in need of mental health care reside in small towns and rural locations. Further, some evidence indicates that mental health concerns may be worse in rural areas. For example, suicide rates among rural adolescents appear to be higher than those for urban adolescents with disparity increasing over time (Fontanella et al., 2015). The picture appears even more grim in countries with fewer resources. For instance, current estimates place 5,000 mental health providers in India, which has an estimated 240 million individuals with mental illness; the majority of these providers do not have training in psychological interventions (Fairburn \& Patel, 2014; Math \& Srinivasaraju, 2010).

This is the big picture we face. We have made significant strides in the development of psychological treatments with significant empirical support, yet we struggle in effectively partnering with clinicians to deploy these tools regularly. And even if every clinician delivered our treatments with maximum effectiveness, we would still fail to reach millions who need help. All of which leads to a key question regarding where we go from here. It is important to note that I do not advocate abandoning current lines of research; there is obvious merit in continuing to refine and create new treatments. But, as noted by Patel (2014), we already know enough to make a meaningful global difference if we expend more resources in other directions. Sample recommendations proposed to increase our impact include an increased focus on prevention and public health approaches, the use of strategic research to change public policy, and utilization of scalable strategies to increase the reach of what we currently have (Brownell \& Roberto, 2015; Fairburn \& Patel, 2014; Fairburn \& Wilson, 2013; Kazdin \& Blase, 2011; Kazdin \& Rabbitt, 2013; Lyon \& Koerner, 2016; Patel, 2014; Patel, Chowdhary, Rahman, \& Verdeli, 2011; Zandberg \& Wilson, 2013). Scalability refers to the degree to which interventions can be scaled-up to reach large populations without significant loss of effectiveness. Such strategies promoted by the above authors include a focus on shorter interventions when treating mental illness (e.g., behavioral activation vs. full cognitive-behavioral therapy [CBT] for depression), increased use of technology, task shifting/sharing with lay providers, and train-the-trainer (TTT) models.

In 2000, Stice and colleagues published the first paper on a new eating disorder (ED) prevention intervention (the Body Project: Stice, Mazotti, Weibel, \& Agras, 2000). Over the past 16 years, a global community of researchers, clinicians, and community stakeholders have partnered to traverse the efficacy-to-effectiveness-to-dissemination/ implementation continuum with this intervention. To date, the Body Project has reached 3.5 million girls and young women in 125 countries. The aim of this paper is to offer a series of six lessons learned from the Body Project in what not to do in translating clinical psychological science to global impact. Framing lessons learned as "what not to do" may seem an unusual way to discuss what we have learned. Large-scale implementation, however, is highly complex and at any given decision point there typically are many forks in the road that can be considered. It is very unlikely that successful experiences with one intervention will lay a definitive road map for all other interventions. However, knowing what not to do (i.e., what paths should be eliminated from consideration because they will likely not work and might even damage progress) is often useful in its own right and can reduce the number of viable options, thus increasing the probability of making a good decision.

\section{The Body Project: Overview and Empirical Support}

The Body Project is a 4-hour small-group intervention for adolescent girls and young adult women. Based on both the theory of cognitive dissonance and the dual pathway model of ED pathology (Festinger, 1957; Stice, 2001), Body Project activities encourage participants to critique the thin-ideal standard of female beauty (Stice \& 
Presnell, 2007). Theoretically, this creates the uncomfortably psychological state of dissonance, which in turn decreases investment in the thin ideal. Per the dual pathway model (Stice, 2001), reductions in thin-ideal internalization then trigger a presumed cascading decrease in the following ED risk factors: body dissatisfaction, negative affect, dieting, and early-stage ED pathology. It is important to note that reducing body dissatisfaction is both a means to the end of reducing ED pathology, but also an end in itself in that body dissatisfaction creates significant misery in many who will not develop an ED. Indeed, body dissatisfaction is associated with the following negative sequelae: depression, suicidality after controlling for depression, unhealthy weight control behaviors, and decreased quality of life (Bearman, Presnell, Martinez, \& Stice, 2006; Crow, Eisenberg, Story, \& Neumark-Stzainer, 2008; Jacobi \& Fittig, 2010; Quick, Eisenberg, Bucchianeri, \& Neumark-Sztainer, 2013; Wilson, Latner, \& Hayashi, 2013). For this reason, and because body dissatisfaction is so ubiquitous among girls and women, many community stakeholders are as, if not more, interested in addressing body dissatisfaction than preventing EDs.

Empirical support for the Body Project is extensive (see Becker \& Stice, in press, for a review). Randomized controlled trials (RCTs) conducted by the original developers of the Body Project support its efficacy and effectiveness in reducing thin-ideal internalization, body dissatisfaction, dieting, negative affect, and ED symptoms, with many effects holding at 1- to 3-year follow-up (Stice, Butryn, Rohde, Shaw, \& Marti, 2013; Stice, Chase, Stormer, \& Appel, 2001; Stice, Trost, \& Chase, 2003; Stice, Marti, Spoor, Presnell, \& Shaw, 2008; Stice, Rohde, Butryn, Shaw, \& Marti, 2015; Stice, Rohde, Gau, \& Shaw, 2009; Stice, Shaw, Burton, \& Wade, 2006). Importantly, the Body Project is one of only four interventions shown to reduce the onset of new ED cases (Martinsen et al., 2014; Stice et al., 2008; Taylor et al., 2006), indicating that it truly can prevent at least some EDs. For instance, the Body Project reduced onset of new ED cases by $60 \%$ in one trial versus assessment-only control (Stice et al., 2008).

Independent researchers have also found positive effects with the Body Project using RCTs, many of which sought to extend results as well as replicate (e.g., Becker, Bull, Schaumberg, Cauble, \& Franco, 2008; Becker, Smith, \& Ciao, 2005, 2006; Cruwys, Haslam, Fox, \& McMahon, 2015; Green, Scott, Diyankova, Gasser, \& Pederson; 2005; Matusek, Wendt, \& Wiseman, 2004; Mitchell, Mazzeo, Rausch, \& Cooke, 2007; Roehrig, Thompson, Brannick, \& van den Berg, 2006; Serdar et al.,
2014). Although many of these trials were limited by shorter follow-ups (i.e., 1-8 months), in an effectiveness trial with 14-month follow-up, Becker et al. (2010) found both a similar pattern of effects relative to an active control and similar within-group effect sizes compared with Stice et al.'s (2006) efficacy RCT at 12 months. Notably, delivery of the Body Project can be task shifted to undergraduate peer leaders, markedly increasing its scalability (Becker et al., 2006, 2008, 2010; Perez, Becker, \& Ramirez, 2010; Stice, Rohde, Durant, Shaw, \& Wade, 2013; Stice, Rohde, Shaw, \& Gau, 2016). Further, Body Project researchers have demonstrated that peer leader training can be task shifted away from doctoral-level trainers with a TTT model (Greif, Becker, \& Hildebrandt, 2015; Kilpela et al., 2014). Combined, task-shifting delivery and use of the TTT model significantly enhance the scalability of the Body Project above and beyond either scaling strategy alone.

Research also supports the theoretical basis of the Body Project. More specifically, high-dissonance induction versions of the Body Project show greater symptom reductions than low-dissonance versions (Green et al., 2005; McMillan, Stice, \& Rohde, 2011). Further, two trials found that reductions in thin-ideal internalization mediated the effects of the Body Project on ED symptom reduction (Seidel, Presnell \& Rosenfield, 2009; Stice, Marti, Rohde, \& Shaw, 2011). Halliwell and Diedrichs (2014) also found that the Body Project eliminated the negative effects of exposure to thin models on body dissatisfaction as compared with a control condition. Last, relative to participants in an educational brochure control condition, participants in the Body Project showed greater reductions in functional magnetic resonance imaging (fMRI)-assessed reward region neural responsivity to thin models and attention region response to thin-ideal statements (Stice, Yokum, \& Waters, 2015).

\section{Dissemination and Implementation: Quick Body Project History}

It is beyond the scope of this paper to provide extensive detail regarding all partnerships that have facilitated global implementation (see Becker et al., 2016; Becker \& Stice, in press; Becker, Stice, Shaw \& Woda, 2009). Instead, this section provides a quick chronological history of key implementation developments and partnerships to set the stage for subsequent lessons learned.

The first major national rollout of the Body Project was conducted in partnership with the Tri Delta national sorority. Tri Delta approached Becker after learning about her work with local sororities at Trinity University via a Tri Delta alumna, who heard 
about the local sorority partnership at a community talk aimed at laypersons. Tri Delta reached out second to (a) an interest in body image and EDs and (b) the alumna's perception that Becker was both respectful of sorority values and appreciative of their organizational power. This was important because researchers are often perceived by sororities as having negative attitudes about their organizations and/or a desire to use them versus respectfully partner with them.

After 2 years of pilot testing delivery of the peer-led task-shifting version of the Body Project in collaboration with Becker, Tri Delta decided to embark on a 5 -year implementation plan with the aim of reaching 20,000 college women in North America. As part of this, Tri Delta rebranded the Body Project as the Reflections Body Image Program; however, because this branding is no longer used, the Body Project name is used throughout this paper. It should be noted that Tri Delta's goal to scale the intervention nationally to 20,000 individuals was the catalyst that led to the development of the TTT model that continues to underpin current large-scale implementation endeavors. Although Tri Delta was unable to track the exact numbers of women reached, they successfully brought the Body Project to over 100 university campuses and sold or granted over 15,000 workbooks between 2008 and 2012. This partnership ended in 2012, in large part due to changes in leadership and vision within the organization.

Overlapping with Tri Delta was a smaller effort by an ED charity in the United Kingdom, the Succeed Foundation. Succeed sought to replicate Tri Delta's success in the United Kingdom. The founder of Succeed learned about Tri Delta and Becker's work via a video developed for a marketing campaign that Tri Delta launched in 2008 to promote the Body Project (see below for additional detail). After extensive discussion with Becker, they collaboratively recruited Diedrichs, a researcher at the Center for Appearance Research, to lead their implementation plan. Although Succeed reached only a few universities and ultimately closed as a charity, thus ending this partnership, it laid the foundation for future success and is thus worth noting.

After the Tri Delta partnership ended, the Body Project community lost most of the North American Body Project implementation infrastructure. Becker and Stice decided to rebuild infrastructure by launching the Body Project Collaborative, a social entrepreneurship company. Social entrepreneurship exists between for-profit and nonprofit organizations (see https://ssir.org/articles/entry/social_ entrepreneurship_the_case_for_definition, for a definition). Whereas some social entrepreneurship companies operate like traditional for-profit companies, albeit with a social mission, others retain a for-profit legal status but operate like nonprofit organizations in that they seek sustainability versus high levels of profitability. The business plan for the Body Project Collaborative, which started with only $\$ 1,000$ in seed money, placed it in the latter category. The primary aim of the Body Project Collaborative was to bring together existing Body Project trainers from the Stice research group and the Becker/Tri Delta implementation team to begin a new sustainable and organized push to expand implementation of the Body Project.

Around the same time as the partnership with Tri Delta was winding down, Diedrichs was invited to join an advisory board for the Dove Self-Esteem Project. This invitation appeared to result in part from Diedrichs's work with Succeed, which had helped increase her public visibility in the UK body image intervention community; the latter consisted of community stakeholders, researchers, government officials, and corporations such as Unilever, which owns the Dove brand. Launched in 2006, the Dove Self-Esteem Project aims to promote positive body image, or "body confidence," in girls globally. It should be noted that Dove's early forays into enhancing body image did not rely on empirically supported interventions and Body Project researchers, including Diedrich and Becker, not infrequently critiqued this during both academic and community presentations and discussions.

Accepting the board invitation was a gamble, as it was unclear if Dove would be willing to take a more evidence-based approach. However, with Diedrich's encouragement, Dove leaders decided to do just that in the development of programming for the World Association of Girl Guides and Girl Scouts (WAGGGS). For this, they commissioned an adaption of the Body Project. The aim was to convert the Body Project into a manual that (a) was compatible with the nonformal educational approach of WAGGGS and (b) could be delivered to millions of girls globally by task-shifting implementation to WAGGGS troop leaders. Dove and WAGGGS also sought to utilize the TTT model developed for Tri Delta. The Tri Delta partnership also played a secondary role with DOVE and WAGGGS. Diedrichs used the Tri Delta partnership to provide evidence to Dove and WAGGGS that Body Project researchers would be willing to learn and respect WAGGGS culture during the adaptation process. Both Dove and WAGGGS reported that this was critical in their decision to 
partner. The final manual (http://www.free-beingme. com/ downloads/) and the task-shifting/TTT implementation plan were collaboratively created by Diedrichs, Becker, Stice, WAGGGS staff, and Dove leadership. To date, WAGGGS reports that 3.5 million girls in 125 countries have been reached; the manual has also been translated into 19 languages. Preliminary outcome research funded by Dove and conducted by Stice and Diedrichs supports the pre-post effectiveness of the Free Being Me adaption (Stice \& Diedrichs, 2016).

Simultaneous to the developing work with Dove, in late 2012, the newly formed Body Project Collaborative began partnering with the U.S.-based National Eating Disorders Association (NEDA). Although these discussions were initiated by the executive director of NEDA, the foundation was laid via conversations at conferences among Body Project researchers and NEDA staff and grassroots stakeholders. Importantly, the ED professional community has been increasingly open to input from stakeholders (e.g., patient/carers can join the Academy of Eating Disorders [AED], which is a professional organization, and attend its conference); this increases the chance for relationships to develop. In our experience, stakeholders appear more likely to reach out to collaborate when they have developed personal relationships with researchers.

The primary aim of NEDA partnership was to create a sustainable and largely self-sufficient implementation capacity within NEDA by training group facilitators and trainers of group facilitators, as well as two NEDA "master" trainers who could train other trainers without having to rehire the Body Project Collaborative. The ongoing NEDA project has two primary branches. One focuses on implementing the Body Project with underserved high school girls in New York City (NYC); to date NEDA has implemented the Body Project in several schools and is expanding its network of NYC community partnerships. The other uses NEDA's existing conference and national network to facilitate increased nationwide Body Project expertise among both clinicians and ED grassroots activists with the aim of expanding use in high schools. Demand for the one-day Body Project training conducted by NEDA staff in conjunction with NEDA's national conference led to the workshop being sold out in both 2015 and 2016 .

In 2013, the Body Project Collaborative also embarked on a pilot partnership with the Eating Recovery Foundation (ERF), which is the nonprofit foundation started by the for-profit Eating Recovery Center (ERC). ERC is one of the largest multisite residential ED treatment programs in the United States. The ERF partnership was the brainchild of a Body Project trainer who went to work for ERC. This trainer repeatedly proposed the idea of a partnership to key ERC leaders. Ultimately, Becker was invited for a meeting and given the opportunity to officially pitch to senior executives a rationale for partnering. After this, ERC agreed to a pilot partnership.

This partnership sought to extend Tri Delta's work by bringing the Body Project to additional North American universities. ERF provides grants to cover the majority of costs associated with bringing a Body Project Collaborative trainer to campus to provide a 2-day TTT training for task-shifted implementation of the Body Project. This 2-day training provides simultaneous training for approximately 12 peer leaders and 3-6 staff trainers. A key component the TTT approach is sustainability. Once staff know how to train peer leaders, the university no longer needs a trainer from outside the university and the Body Project can be scaled-up by training more peer leaders. Because many universities want to provide students leadership and peer educator experiences, the Body Project often can be cost-effectively folded into existing infrastructure once the initial training is completed. After a 2-year pilot, the ERF agreed to fund 85 new grants over 5 years. To date, across both the pilot and the first year of the 5 -year period, this partnership has trained 355 student peer leaders and 223 staff at 41 universities.

In 2014, the Body Project Collaborative launched a partnership with Comenzar de Nuevo (CdeN), a nonprofit residential treatment program for EDs in Mexico. The CdeN founder and chief medical officer initiated the partnership after attending a Body Project workshop at the AED annual conference. The founder was a community stakeholder, who would not have attended the conference if AED limited membership and attendance to professionals. The chief medical officer also had relationships with multiple Body Project researchers via the AED.

CdeN sought to establish a foundation for large-scale implementation of the Body Project throughout Latin America. Mimicking the NEDA approach, CdeN hosted 5 days of training in which two Body Project Collaborative trainers trained facilitators, trainers, and master trainers. Posttraining, CdeN spent 6-9 months creating a marketing, fund-raising, and business plan to address the challenges associated with broad intervention implementation in low-income countries. To date, $\mathrm{CdeN}$ has trained facilitators and trainers at three universities in Mexico. They have also held trainings in Chile and the Dominican Republic, and are scheduling trainings in four new cities in 
Mexico, as well as Argentina, Ecuador, and San Salvador.

\section{Six Lessons Learned About What Not to Do in Expanding Our Impact}

LESSON I: DO NOT RELY ON STANDARD STATISTICAL AND ACADEMIC STRATEGIES TO ENGAGE PEOPLE

As scientist-practitioners, data and nuanced interpretation of research studies serve as foundations for our work. There is nothing wrong with this for those of us who seek to discover what interventions work for whom under various circumstances. Too often, however, we expect this same approach to carry the day with full-time clinicians and people outside our field. Although some in these constituencies are convinced by the same numbers that seem so compelling for us, many are not. We need to explore other strategies.

This lesson first became clear during strategic planning for the launching of the Tri Delta implementation plan when Tri Delta invited its public relations (PR) consultant to our meetings. Tri Delta has extensive experience with large-scale program deployment. Tri Delta averages around 13,500 collegiate members scattered across approximately 130 North American chapters at any given time. Program implementation is a large part of their day-to-day operations. The PR consultant stated that we needed the following four components to successfully build excitement about the Body Project: digestible and compelling statistics about both the problem and the intervention, a marketing campaign with a hook, branding, and testimonials. She defined digestible statistics as something that any tired mother who was preparing breakfast for her kids while watching morning television could understand in less than 30 seconds. In other words, stating that "the Body Project produces statistically significant reductions in body dissatisfaction, dietary restraint, and eating disorder symptoms as assessed by the Eating Disorder Examination Questionnaire at 1-year follow-up relative to a control condition" is not digestible. In contrast, " $67 \%$ of women withdraw from lifeengaging activities, such as going to school or the doctor, because they feel badly about how they look" is digestible. Using more comparable examples, "the Body Project reduced onset of eating disorders by $60 \%$ " is less digestible than "For every 100 girls who go through the Body Project, nine fewer girls will develop eating disorders.”

Following the PR consultant's advice, Tri Delta rebranded the Body Project and developed an advocacy week/marketing campaign (i.e., Fat Talk
Free Week) that was launched with a very engaging video full of digestible statistics (https://www. youtube.com/watch?v=KjqqVbcwpbM). They sought major media coverage to build excitement both inside and outside their own organization. They also created promotional material that ranged from T-shirts stating "Friends Don't Let Friends Fat Talk" to erasers labeled with "Erase Fat Talk," and used peer-leader testimonials for promotion. After Fat Talk Free Week became an unexpected success, they created a new video (e.g., https://www.youtube.com/ watch?v=4CuMJybvAh8) and social media campaigns, which also used testimonials. Tri Delta is not alone among our partners in highlighting the importance of coherent marketing. Dove and WAGGGS developed a moving video with digestible statistics, to promote their Body Project adaptation (https://www.youtube.com/watch? v $=Q_{-}$ wjYltJGLw). WAGGGS also hosted a Free Being Me festival at their world center in India (http://freebeing-me.com/about/festival/) and created a special badge that can be earned by all who complete Free Being Me. As noted above, CdeN spent 9 months developing a marketing program before beginning to roll out the Body Project in Latin America. They also created an entertaining video.

None of this should be surprising. We teach undergraduates about the power of testimonials (Stanovich, 1998), and psychology research underpins much of marketing. Marketing plays a key role in the widespread use of psychotropic medications (Healy, 2012). Research also demonstrates that how we promote CBT influences the degree to which clinicians are interested in getting trained in CBT. More specifically, Stewart and Chambless (2010) found that case study material made empirically supported treatments more interesting to clinicians in private practice and increased their interest in becoming trained; inclusion of standard (i.e., academic) statistical information conferred no additional benefit above that obtained with the case study.

Despite this, to date there has been no comprehensive marketing campaign to promote CBT to either clinicians or the general public to my knowledge. One could, of course, argue that we do not have a marketing budget to pay for such a campaign, but as will be noted in Lesson 3, we need to think more creatively about finding money to accomplish our collective goals. Also, few of us gather data in a way that produces the digestible statistics needed to better convey the success of our interventions and the importance of the problems we address. For instance, frequencies are more digestible and better communicate the degree to which a problem is normative, yet many researchers report means 
(Fiske, Fallon, Blissmer, \& Redding, 2014), which are often meaningless to laypersons, including policy makers. To meet Tri Delta's need for digestible statistics, we included different questions in our research. Importantly, Brownell and Roberto (2015) have argued that changing government policy means asking strategic questions that address the interests of policy makers. I argue we will need to do this to convince other groups of the importance of what we do and the effectiveness of our interventions. In sum, large-scale reach, in our experience, is not built solely with standard academic arguments and statistics.

LESSON 2: DO NOT IGNORE THE IMPORTANT LITERATURE ON COMMUNITY PARTICIPATORY RESEARCH

Examples from Lesson 1 beg the question as to how we can better engage community stakeholders so that we can benefit from their expertise and their resources. All Body Project partnerships rely heavily on the principles of community participatory research (CPR) regardless of whether or not our main goal is research or clinical implementation (see Becker et al., 2009, for additional detail). CPR is well recognized in nursing, social work, and public health (Israel, Eng, Schultz, \& Parker, 2005), yet receives relatively little discussion in the CBT field. For instance, a search of "community participatory" for this journal yielded no hits. A similar search in Behaviour Research and Therapy, which has the same publisher and search engine, produced just five hits; all articles were associated with the Body Project. Now this is not to say that many CBT researchers are not using at least some of the strategies included in CPR; indeed if you approach research and implementation partnerships in the same collaborative manner as you approach CBT, you will likely use some tenets of CPR. Yet, there is something to be gained by being explicitly aware of this literature, which can teach us a tremendous amount about how to form the types of partnerships needed to advance our collective agenda.

For those not familiar with CPR (also called community participatory action research), Israel et al. (2005) outline nine components of CPR; although not all components are included in every study using CPR, these factors are shared across this style of doing research. In brief, CPR brings stakeholders to the table as equal partners in designing and conducting research (or developing and delivering an implementation plan). CPR can be contrasted with traditional research in which researchers develop a research plan and then implement the plan with participants, who have limited, if any voice, in the research design or process. The factors outlined by
Israel et al. (2005) include realizing that communities are entities to which individuals belong and connect; creating truly equitable and collaborative partnerships; building upon community strengths; fostering co-learning and capacity building for everyone involved; balancing the importance of creating new knowledge with the delivery of useful intervention so that every constituency benefits in the present; recognizing the multiple determinants of health behavior and addressing the immediate impact of health problems; promoting a collaborative, cyclical, iterative process; sharing results in a manner that is respectful and beneficial to partner communities; and making a long-term commitment to the project, the community, and future sustainability.

The extensive literature on CPR offers many tips for the developing of strategic community partnerships. This is critical to our collective agenda for three reasons. First, we need partners to address our own limitations-no one field trains people to excel in doing everything. Indeed, as noted above, we have learned a tremendous amount from our partners with regard to the marketing of psychological interventions. We have also learned to think on a much larger scale than we likely ever would have done on our own. When I first started working with Tri Delta, reaching a few hundred women a year seemed like an accomplishment. Now, thanks to all of our partners, we strive to impact countries and millions.

Second, many stakeholder communities want increased access to empirically supported psychological interventions and are natural allies. For instance, the ED carer organization FEAST is very frustrated about the degree to which its members struggle to find therapists who can competently deliver empirically supported treatments for EDs (Collins, personal communication, 2013). We need partnership strategies to navigate the real challenges in partnering with organizations that have a very different membership mix. CPR strategies could also help ABCT begin to think about how to regularly interact with community stakeholder organizations, including patient/carers, to advance agreed-upon goals.

Finally, good partnerships beget more partners. As noted above, even though the partnership with Tri Delta ultimately ended, it played a pivotal role in helping us establish the Dove and WAGGGS partnership. In truth, the Tri Delta partnership laid the foundation for all of our other partnerships. In addition, the Tri Delta partnership was actually built upon the earlier local sorority partnerships. Body Project partnerships have also served as a foundation for parallel research with female athletes. When people observe you respecting and 
working competently with other communities, you gain credibility and they become more interested in working with you; they then reach out to initiate partnerships. Further, as you gain skill in working with different constituencies you begin to build new communities. As implied above, we now view everyone who works with the Body Project as being part of an informal global community. We go out of our way to make introductions between groups and highlight this community during academic presentations. The more we view ourselves as a collective, the more community we build and the more momentum we gain.

\section{LESSON 3: DO NOT OVERLY RELY ON RESEARCH GRANT FUNDING}

Research grants have obvious benefits. For some of us, they are required to sustain our employment. In addition, they make some things possible and many things easier. For instance, one of the most important Body Project studies (i.e., Stice et al., 2006, 2008) would have been impossible to conduct without significant support from the National Institute of Mental Health (NIMH). Indeed, NIMH funded a substantial amount of the research that provides the evidence base for the Body Project. We cannot do without research grants.

At the same time, grants have downsides. More specifically, they may remove real-world contingencies. For instance, I started task shifting Body Project delivery to undergraduates because I hit the scalability problem early in my program of research; this happened when the sororities at my university announced that they wanted to run 12 simultaneous groups. Now if I had had grant funding, I would have simply paid a clinician to run the groups. Indeed, if I had been faculty at a university with a graduate program in clinical psychology, I would have recruited graduate students to run the groups. Because I had neither, I faced the same problem that intervention implementers in low-income countries face (i.e., lack of skilled providers and lack of funds to access additional providers; Patel et al., 2011). Perhaps not surprisingly, I started testing the same solution, task shifting. Eleven years later, task-shifted delivery of the Body Project is the dominant modality used around the world. The availability of the task-shifting approach was also critical in Tri Delta's decision to form that seminal partnership. As such, I would argue that facing real-world contingencies without the ability to buy our way out of problems can force us to ask important research questions and develop needed innovations.

Another reason for moving beyond research grants is the shortage of those opportunities for scientists interested in implementing specific interventions. For instance, although NIMH has a dissemination/implementation funding mechanism, the aim of that mechanism is to identify big-picture lessons that can be applied to many different interventions across different problems versus studying specific issues related to implementing one specific intervention for one specific problem. In other words, NIMH is not a good resource if I want to study implementation of the Body Project in rural U.S. counties because I think that will help with implementation in Africa.

We also need to learn to move beyond research funding because, almost by definition, research funding is temporary. Long-term sustainable implementation of interventions requires sustainable funding, which means searching broadly for resources from many sources. To date, the Body Project community has relied on a variety of strategies. First, we get some of our funding directly from our community partners, which range from nonprofit organizations (e.g., ERF, $\mathrm{CdeN}$ ) to a large multinational corporation (i.e., Unilever). However, forming a partnership does not mean a priori that an organization will invest its financial resources. Indeed, convincing organization decision makers who hold the proverbial purse strings to release funding has often required Body Project researchers to make an argument for said allocation of resources. Pitching to boards and CEOs can be quite different from writing a research grant; you may get as little as 20 minutes to bring smart but naïve (with respect to your topic) individuals up to speed on both the problem and your solution. Optimally, you tie your goals back to the broader goals of their organization, which are easier to identify if you have been following principles of CPR. Having digestible statistics and avoiding academic jargon also helps.

In collaboration with our partners, we have also applied for foundation- and state-based grants that were aimed at enhancing the lives of specific populations versus conducting research. Some of these grants were easier to obtain because they were submitted by our partner organizations, albeit with our input. Our partners are also often adept at traditional fund-raising. CdeN developed a "grandfather" program in which donors sponsor a particular high school or college, covering the costs of a Body Project training. They also found funding from a grocery store chain. Tri Delta created sponsorship levels for Fat Talk Free Week, highlighting the utility of a marketing campaign. In some cases, individuals whose lives have been negatively impacted by EDs have made donations 
to our nonprofit partners in support of the Body Project.

Social entrepreneurship, along with a solid business plan, is an additional option that seems to be flying under many people's radar. As noted above, the Body Project Collaborative is technically a for-profit company that operates like a nonprofit in that our primary mission is to benefit society and be sustainable versus highly profitable. For those of us who retain "day jobs" in academia or private practice and simply want an organization to advance dissemination and implementation of an intervention, social entrepreneurship can be more practical than starting a nonprofit organization. It is both easier and cheaper to form a limited liability company (LLC) as compared to a nonprofit. You also need less time to run the company as you are not required to have a board of directors. Liability insurance may be cheaper as you do not need to insure a board of directors. Last, a small social entrepreneurship company can often respond more quickly to market demands and you can often get by with less infrastructure. This does not undermine the importance of nonprofit organizations. As noted above, many of our partners are nonprofit. Social entrepreneurship just adds another financial tool at our disposal.

LESSON 4: DO NOT STAY IN YOUR COMFORT ZONE OR BE AFRAID TO FAIL

Many of us in the Body Project community will freely admit that we often find ourselves outside our comfort zone and/or thinking, I can't believe I am doing this. The first time my undergraduate research assistants and I task shifted the Body Project by simultaneously running approximately 100 participants (via 36 peer leaders) in an unfunded RCT, I literally thought, This is crazy. Colleagues later confirmed that they agreed with that assessment. We succeeded (much to our surprise), but the process was quite anxiety provoking. Running Tri Delta's Body Image Academy with our new TTT model for the first time was a similar experience.

To date, despite having zero desire to do so, I have had to seriously engage with the media in print, on TV (sitting on a yoga ball), and on the radio. I have found myself dancing in a flash dance mob in front of the Alamo; the video of this event lives in perpetuity on YouTube (spoiler-I am not a dancer and managed to hide in the back). I never intended to join a sorority, but at age 40 , I became an honorary member so as not to reject Tri Delta's highest honor. I was the sole initiate and there were five times more people at this event than my wedding. Creating a business and business plan was also outside my personal comfort zone. These events are tip-of-the-iceberg examples regarding what I and other Body Project researchers have done over the past 16 years, and there is broad consensus among this group that our willingness to do things that sometimes make us extremely uncomfortable or anxious has been critical to any success we have had.

When aiming for seemingly unrealistic goals, we like to remind ourselves that the worst-case scenario is that you fail. And in some cases we did; ultimately, the partnership with Tri Delta failed. Yet you learn as much from failure as success in many cases. Four years after the ending of that partnership, we have expanded our impact beyond our wildest expectations.

\section{LESSON 5: DO NOT BE RELUCTANT TO SACRIFICE SOME EFFECT SIZE TO REACH MORE PEOPLE}

Kazdin and Blase (2011) emphasize our need to develop a portfolio of strategies, ranging from prevention through tertiary care, so as to maximize our collective impact. Although a key aim of much psychological intervention research is to find ways to maximize effect sizes, Kazdin and Blase argue that interventions with larger effect sizes are not always better than those with smaller ones. More specifically, they propose that interventions with weaker but reliable effects that are highly scalable and cost-effective are worth having because, on a populationwide basis, a small but consistent effect that can be magnified by millions can lead to meaningful benefit.

Body Project researchers have never let go of the goal to maximize intervention effects. However, we have also collectively agreed that losing some effect size in exchange for widespread implementation may be acceptable. For instance, when we launched the Dove/WAGGGS partnership, we recognized that it was likely that effects of a globally implemented and untested adaptation of the Body Project would be reduced relative to those found in the best efficacy and effectiveness trials. In addition, we recognized that this implementation project faced long odds in terms of actually reducing the onset of any ED. Yet, we also believed that smaller changes in body dissatisfaction multiplied over millions of interconnected girls and their mentors could still potentially improve quality of life for many girls and possibly begin to shift social norms within their friend groups. As a result, we were willing to be somewhat more flexible in finding common ground (per CPR methods) with our community partners. As noted above, early 
research results from this partnership are proving to be very encouraging.

Obviously, there is a point of diminishing return in which the tradeoff between effect size and number of people reached no longer makes sense. But it is possible that there is more flexibility than we realize regarding where that point is across interventions. For instance, Kazdin and Blase (2011) note that having physicians briefly recommend smoking cessation to patients who smoke reduces smoking by an additional $2.5 \%$ compared with no intervention. This difference is too small to be meaningful in most RCTs; yet if implemented by all physicians, it can make a populationwide difference when delivered as part of a portfolio of interventions.

\section{LESSON 6: DO NOT ENTIRELY GIVE UP COPYRIGHT AND/OR BECOME TOO \\ ATTACHED TO ROYALTIES}

Unfortunately, our experiences with the Body Project strongly reinforce the notion that both cost and the ability to tailor materials for various constituencies matter when striving for large-scale implementation. Your ability to control these depends on the degree to which you retain some author rights through copyright. For instance, the Body Project manual was published shortly before Tri Delta made the decision to embark on its implementation project. We immediately ran into what became known as the "manual problem." More specifically, the published version of the manual (four sessions and designed for clinicians) was not the version we needed (two sessions and designed for peer leaders). Note that task shifting, which is great for increasing scalability, often requires tailored materials designed to address the fact that lay providers lack professional training. Because a publisher held full copyright, however, we could not simply implement on a large scale without being in violation of copyright laws. Fortunately, Tri Delta had the resources and motivation to custom order the version of the manual that we needed and to absorb that cost when implementing with their own members. It is important to note that publishers will not undertake custom publishing for small quantities; thus upfront costs for tailored manuals can cost tens of thousands of dollars. Understandably, Tri Delta sold the manuals and workbooks to nonmember groups that attended Body Image Academy, but relatively early on we heard from universities that manual costs were an impediment to large-scale rollout even though Tri Delta sold the manuals largely at cost.
We encountered the manual problem again with the Succeed Foundation as they not only needed the two-session, peer-leader version but also needed the American English used in the manual translated into British English; we all agreed task-shifted groups would likely be derailed by laughter over language differences if we used the American English version in the UK. Once again, we were lucky, and Succeed rallied the needed resources for custom publishing. It was rapidly becoming clear, however, that inability to tailor manuals as we saw fit without having to purchase large numbers of custom manuals was a barrier to large-scale implementation.

In 2012, Stice negotiated the right to give away derivative scripts (i.e., the basic content for the actual sessions) for free via a Web site. Although this means that no one receives royalties for the free scripts, we can now create derivation after derivation as needed. For instance, we can maintain a Mexican Spanish version and a Spanish Spanish version with ease. We also can easily modify materials to address cultural differences that matter little regarding the core intervention but matter a lot when working with a combined task-shifting/TTT model. When community partners report getting negative feedback on some phrasing secondary to language drift (e.g., "curvy" developed new body image connotations over time) we can adjust the language. We still encourage universities and partners to buy "reference" copies of the official published manual, which contains additional information not included in the derivative scripts, out of respect for the publisher. It is clear, however, that making the intervention as inexpensive as possible and providing tailored materials when needed significantly facilitates large-scale implementation.

\section{Application of Lessons to Treatment Interventions}

The present paper describes lessons learned about what not to do in translating efficacy and effectiveness research into large-scale clinical impact based on experiences with a prevention intervention. As such, it seems important to ask to what degree lessons learned with a prevention intervention will translate to treatment interventions. Although there are clear differences between prevention and treatment (e.g., nonclinical vs. clinical target population), it would appear that most, if not all, of the lessons described likely apply to treatment interventions. For instance, cost (Lesson 6) matters at both the prevention and treatment levels of intervention. Similarly, CPR approaches (Lesson 2) have long been used by other fields when interacting with clinical populations (Israel et al., 2005). Further, becoming overly dependent on grant funding and losing sight of 
real-world contingencies that can impact implementation (Lesson 3 ) is equally problematic at the levels of prevention and treatment. Nonetheless, there are differences. Treatment interventions tend to be more complex and thus scaling with task shifting can be more challenging. This has been done, however, in developing countries, which suggests that it can be done in more resource-rich countries (e.g., Patel et al., 2011). Similarly, the types of organizations with which treatment researchers must contend (e.g., insurance companies; city, county, and state agencies) differ from the types of organizations with which Body Project researchers have found collaboration. Use of CPR methods, however, still seems a good tool for establishing these partnerships. In sum, although the devil may be in the details and there is no doubt that the details will differ for prevention and treatment interventions, the types of lessons offered here still appear relevant.

\section{Conclusion}

ABCT members continue to make steady progress in advancing ABCT's mission, yet we still have significant work to do when it comes to addressing both the research-practice gap and Kazdin and colleagues' (Kazdin, 2016; Kazdin \& Blase, 2011; Kazdin \& Rabbitt, 2013) treatment gap. The Body Project community considers itself fortunate in the degree of success we have collectively achieved in navigating the efficacy-effectiveness-dissemination/ implementation continuum of intervention development and delivery. Hopefully, lessons learned from the Body Project can benefit other endeavors.

\section{Conflict of Interest Statement}

The author is co-director of the Body Project Collaborative.

\section{References}

Bearman, S. K., Presnell, K., Martinez, E., \& Stice, E. (2006). The skinny on body dissatisfaction: A longitudinal study of adolescent girls and boys. Journal of Youth Adolescence, 35, 217-229. http://dx.doi.org/10.1007/s10964-005-9010-9

Becker, C. B., Bull, S., Schaumberg, K., Cauble, A., \& Franco, A. (2008). Effectiveness of peer-facilitated eating disorders prevention: A replication trial. Journal of Consulting and Clinical Psychology, 76, 347-354. http://dx.doi.org/10. 1037/0022-006X.76.2.347

Becker, C. B., Perez, M., Kilpela, L. S., Diedrichs, P. C., Trujillo, E., \& Stice, E. (2016). Engaging stakeholder communities as body image intervention partners: The Body Project as a case example. Eating Behaviors. http://dx.doi.org/10.1016/j. eatbeh.2016.03.015

Becker, C. B., Smith, L. M., \& Ciao, A. C. (2005). Reducing eating disorder risk factors in sorority members: A randomized trial. Behavior Therapy, 36, 245-253. http://dx.doi.org/ 10.1016/S0005-7894(05)80073-5

Becker, C. B., Smith, L. M., \& Ciao, A. C. (2006). Peer-facilitated eating disorder prevention: A randomized effectiveness trial of cognitive dissonance and media advocacy. Journal of Counseling Psychology, 53, 550-555. http://dx.doi.org/10. 1037/0022-0167.53.4.550

Becker, C. B., \& Stice, E. (2017). From efficacy to effectiveness to broad implementation: Evolution of the Body Project. Journal of Consulting and Clinical Psychology. in press.

Becker, C. B., Stice, E., Shaw, H., \& Woda, S. (2009). Use of empirically-supported interventions for psychopathology: Can the participatory approach move us beyond the research-to-practice gap? Behaviour Research and Therapy, 47, 265-274. http://dx.doi.org/10.1016/j.brat.2009.02.007

Becker, C. B., Wilson, C., Williams, A., Kelly, M., McDaniel, L., \& Elmquist, J. (2010). Peer-facilitated cognitive dissonance versus healthy weight eating disorders prevention: A randomized comparison. Body Image, 7, 280-288. http://dx.doi.org/ 10.1016/j.bodyim.2010.06.004

Brownell, K. D., \& Roberto, C. A. (2015). Strategic science with policy impact. The Lancet, 385, 2445-2446. http://dx.doi. org/10.1016/S0140-6736(14)62397-7

Crow, S., Eisenberg, M. E., Story, M., \& Neumark-Sztainer, D. (2008). Suicidal behavior in adolescents: Relationship to weight status, weight control behaviors, and body dissatisfaction. International Journal of Eating Disorders, 41, 82-87. http://dx.doi.org/10.1002/eat.20466

Cruwys, T., Haslam, S. A., Fox, N. E., \& McMahon, H. (2015). "That's not what we do": Evidence that normative change is a mechanism of action in group interventions. Behaviour Research and Therapy, 65, 11-17. http://dx.doi.org/10. 1016/j.brat.2014.12.003

Fairburn, C. G., \& Patel, V. (2014). The global dissemination of psychological treatments: A road map for research and practice. American Journal of Psychiatry, 171(5), 495-498. http://dx.doi.org/10.1176/appi.ajp.2013.13111546

Fairburn, C. G., \& Wilson, G. T. (2013). The dissemination and implementation of psychological treatments: Problems and solutions. International Journal of Eating Disorders, 46(5), 516-521. http://dx.doi.org/10.1002/eat.22110

Festinger, L. (1957). A theory of cognitive dissonance. Stanford, CA: Stanford University Press.

Fiske, L., Fallon, E. A., Blissmer, B., \& Redding, C. A. (2014). Prevalence of body dissatisfaction among United States adults: Review and recommendations for future research. Eating Behaviors, 15(3), 357-365. http://dx.doi.org/10. 1016/j.eatbeh.2014.04.010

Fontanella, C. A., Hiance-Steelesmith, D. L., Phillips, G. S., Bridge, J. A., Lester, N., . . Campo, J. V. (2015). Widening rural-urban disparities in youth suicides, United States, 1996-2010. JAMA Pediatrics, 169, 466-473. http://dx.doi. org/10.1001/jamapediatrics.2014.3561

Green, M., Scott, N., Diyankova, I., Gasser, C., \& Pederson, E. (2005). Eating disorder prevention: An experimental comparison of high level dissonance, low level dissonance, and notreatment control. Eating Disorders, 13, 157-169. http://dx. doi.org/10.1037/a0024351

Greif, R., Becker, C. B., \& Hildebrandt, T. (2015). Reducing eating disorder risk factors: A pilot effectiveness trial of a train-the-trainer approach to dissemination and implementation. International Journal of Eating Disorders, 48, 1122-1131. http://dx.doi.org/10.1002/eat.22442

Halliwell, E., \& Diedrichs, P. (2014). Testing a dissonance body image intervention among young girls. Healthy Psychology, 33, 201-204. http://dx.doi.org/10.1037/a0032585

Healy, D. (2012). Pharmageddon. Berkeley: CA: University of California Press.

Israel, B., Eng, E., Schulz, A., \& Parker, E. (2005). Introduction to methods in community-based participatory research for health. In B. A. Israel, E. Eng, A. J. Shulz, \& E. A. Parker 
(Eds.), Methods in community-based participatory research for health (pp. 3-26). San Francisco, CA: Jossey-Bass.

Jacobi, C., \& Fittig, E. (2010). Psychosocial risk factors for eating disorders. In W. Stewart Agras (Ed.), The Oxford handbook of eating disorders. New York, NY: Oxford University Press.

Kazdin, A. E. (2016). Closing the research-practice gap: How, why, and whether. Clinical Psychology: Science and Practice, 23, 201-206. http://dx.doi.org/10.1111/cpsp.12155

Kazdin, A. E., \& Blase, S. L. (2011). Rebooting psychotherapy research and practice to reduce the burden of mental illness. Perspectives on Psychological Science, 6, 21-37. http://dx. doi.org/10.1177/1745691610393527

Kazdin, A. E., \& Rabbitt, S. M. (2013). Novel models for delivering mental health services and reducing the burdens of mental illness. Clinical Psychological Science, 1, 170-191. http://dx.doi.org/10.1177/2167702612463566

Kilpela, L. S., Hill, K., Kelly, M. C., Elmquist, J., Ottoson, P., Keith, D., ... Becker, C. B. (2014). Reducing eating disorder risk factors: A controlled investigation of a blended task-shifting/ train-the-trainer approach to dissemination and implementation. Behaviour Research and Therapy, 63, 70-82. http://dx. doi.org/10.1016/j.brat.2014.09.005

Lyon, A. R., \& Koerner, K. (2016). User-centered design for psychosocial intervention development and implementation. Clinical Psychology: Science and Practice, 23, 180-200. http://dx.doi.org/10.1111/cpsp.12154

Martinsen, M., Bahr, R., Borrensen, R., Holme, I., Pensgaard, A. M., \& Sundgot-Borgen, J. (2014). Preventing eating disorders among young elite athletes: A randomized controlled trial. Medicine \& Science in Sports \& Exercise, 46, 435-447. http://dx.doi.org/10.1249/MSS.0b013e3182a702fc

Math, S. B., \& Srinivasaraju, R. (2010). Indian psychiatric epidemiological studies: Learning from the past. Indian Journal of Psychiatry, 52(Suppl. 1), S95-S103. http://dx.doi. org/10.4103/0019-5545.69220

Matusek, J. A., Wendt, S. J., \& Wiseman, C. V. (2004). Dissonance thin-ideal and didactic healthy behavior eating disorder prevention programs: Results from a controlled trial. International Journal of Eating Disorders, 36, 376-388. http://dx.doi.org/10.1002/eat.20059

McMillan, W., Stice, E., \& Rohde, P. (2011). High- and low-level dissonance-based eating disorder prevention programs with young women with body image concerns: An experimental trial. Journal of Consulting and Clinical Psychology, 79, 129. http://dx.doi.org/10.1037/a0022143

Mitchell, K. S., Mazzeo, S. E., Rausch, S. M., \& Cooke, K. L. (2007). Innovative interventions for disordered eating: Evaluating dissonance-based and yoga interventions. International Journal of Eating Disorders, 40(2), 120-128. http://dx.doi.org/10.1002/eat.20282

Patel, V. (2014). Global perspective on behavioral implementation science. Keynote address at the 20th Annual Eating Disorders Research Society meeting, San Diego, CA.

Patel, V., Chowdhary, N., Rahman, A., \& Verdeli, H. (2011). Improving access to psychological treatments: Lessons from developing countries. Behaviour Research and Therapy, 49, 523-528. http://dx.doi.org/10.1016/j.brat. 2011.06.012

Perez, M., Becker, C. B., \& Ramirez, A. (2010). Transportability of an empirically supported dissonance-based prevention program for eating disorders. Body Image, 7, 179-186. http://dx.doi.org/10.1016/j.bodyim.2010.02.006

Quick, V., Eisenberg, M. E., Bucchianeri, M. M., \& Neumark-Sztainer, D. (2013). Prospective predictors of body dissatisfaction in young adults 10 -year longitudinal findings. Emerging Adulthood, 1, 271-282. http://dx.doi. org/10.1177/2167696813485738

Roehrig, M., Thompson, J. K., Brannick, M., \& van den Berg, P. (2006). Dissonance-based eating disorder prevention program: A preliminary dismantling investigation. International Journal of Eating Disorders, 39, 1-10. http://dx.doi. org/10.1002/eat.20217

Seidel, A., Presnell, K., \& Rosenfield, D. (2009). Mediators in the dissonance eating disorder prevention program. Behaviour Research and Therapy, 47(8), 645-653. http://dx.doi. org/10.1016/j.brat.2009.04.007

Serdar, K., Kelly, N., Palmberg, A., Lydecker, J., Thornton, L., Tully, C., \& Mazzeo, A. (2014). Comparing online and face-to-face dissonance-based eating disorder prevention. Eating Disorders, 22, 244-260. http://dx.doi.org/10.1080/ 10640266.2013.874824

Stanovich, K. E. (1998). How to think straight about psychology. Boston, MA: Pearson Allyn and Bacon.

Stewart, R. E., \& Chambless, D. L. (2010). Interesting practitioners in training in empirically supported treatments: Research reviews versus case studies. Journal of Clinical Psychology, 66, 73-95. http://dx.doi.org/10.1002/jclp.20630

Stice, E. (2001). A prospective test of the dual-pathway model of bulimic pathology: Mediating effects of dieting and negative affect. Journal of Abnormal Psychology, 110, 124-135. http://dx.doi.org/10.1037/0021-843X.110.1.124

Stice, E., Butryn, M., Rohde, P., Shaw, H., \& Marti, N. (2013). An effectiveness trial of a new enhanced dissonance eating disorder prevention program among female college students. Behaviour Research and Therapy, 51, 862-871. http://dx. doi.org/10.1016/j.brat.2013.10.003

Stice, E., Chase, A., Stormer, S., \& Appel, A. (2001). A randomized trial of a dissonance-based eating disorder prevention program. International Journal of Eating Disorders, 29, 247-262. http://dx.doi.org/10.1002/eat.1016

Stice, E., \& Diedrichs, P. (2016). Global implementation of a dissonance-based eating disorder prevention program. Presentation at the Eating Disorder Research Society meeting in New York, NY.

Stice, E., Marti, C. N., Spoor, S., Presnell, K., \& Shaw, H. (2008). Dissonance and healthy weight eating disorder prevention programs: Long-term effects from a randomized efficacy trial. Journal of Consulting and Clinical Psychology, 76, 329-340. http://dx.doi.org/10.1037/0022-006X.76.2.329

Stice, E., Mazotti, L., Weibel, D., \& Agras, W. S. (2000). Dissonance prevention program decreases thin-ideal internalization, body dissatisfaction, dieting, negative affect, and bulimic symptoms: A preliminary experiment. International Journal of Eating Disorders, 27, 206-217.

Stice, E., \& Presnell, K. (2007). The body project: Promoting body acceptance and preventing eating disorders. Facilitator guide and workbook. New York, NY: Oxford University Press.

Stice, E., Rohde, P., Butryn, M., Shaw, H., \& Marti, N. (2015). Effectiveness trial of a selected dissonance-based eating disorder prevention program with female college students: Effects at 2- and 3-year follow-up. Behaviour Research and Therapy, 71, 20-26. http://dx.doi.org/10.1016/j.brat.2015.05.012

Stice, E., Rohde, P., Durant, S., Shaw, H., \& Wade, E. (2013). Effectiveness of peer-led dissonance-based eating disorder prevention groups: Results from two randomized pilot trials. Behaviour Research and Therapy, 51, 197-206. http://dx. doi.org/10.1016/j.brat.2013.01.004

Stice, E., Rohde, P., Gau, J., \& Shaw, H. (2009). An effectiveness trial of a dissonance-based eating disorder prevention program for high-risk adolescent girls. Journal of 
Consulting and Clinical Psychology, 77, 825-834. http://dx. doi.org/10.1037/a0016132

Stice, E., Rohde, P., Shaw, H., \& Gau, J. (2011). An effectiveness trial of a selected dissonance-based eating disorder prevention program for female high school students: Long-term effects. Journal of Consulting and Clinical Psychology, 79, 500-508. http://dx.doi.org/10. 1037/a0024351

Stice, E., Rohde, P., Shaw, H., \& Gau, J. (2016). Implementation trial of clinician-led, peer-led, and internet-delivered dissonance-based eating disorder prevention programs. Poster presented at the Association for Behavioral and Cognitive Therapies, New York, NY.

Stice, E., Shaw, H., Burton, E., \& Wade, E. (2006). Dissonance and healthy weight eating disorder prevention programs: A randomized efficacy trial. Journal of Consulting and Clinical Psychology, 74, 263-275. http://dx.doi.org/10.1037/0022006X.74.2.263

Stice, E., Trost, A., \& Chase, A. (2003). Healthy weight control and dissonance-based eating disorder prevention programs: Results from a controlled trial. International Journal of Eating Disorders, 33, 10-21. http://dx.doi.org/10.1002/eat.10109

Stice, E., Yokum, S., \& Waters, A. (2015). Dissonance-based eating disorder prevention program reduces reward region response to thin models: How actions shape valuation. PLoS ONE, 10(12), e0144530. http://dx.doi.org/10.1371/ journal.pone. 0144530

Taylor, C. B., Bryson, S., Luce, K. H., Cunning, D., Doyle, A. C., Abascal, L. B., ... Wilfley, D. E. (2006). Prevention of eating disorders in at-risk college-age women. Archives of General Psychiatry, 63, 881-888. http://dx.doi.org/10.1001/archpsyc. 63.8.881

Teachman, B. A., Drabick, D. A., Hershenberg, R., Vivian, D., Wolfe, B. E., \& Goldfried, M. R. (2012). Bridging the gap between clinical research and clinical practice: Introduction to the special section. Psychotherapy, 49, 97. http://dx.doi. org/10.1037/a0027346

Wilson, R. E., Latner, J. D., \& Hayashi, K. (2013). More than just body weight: The role of body image in psychological and physical functioning. Body Image, 10, 644-647. http:// dx.doi.org/10.1016/j.bodyim.2013.04.007

Zandberg, L. J., \& Wilson, G. T. (2013). Train-the-trainer: Implementation of cognitive behavioural guided self-help for recurrent binge eating in a naturalistic setting. European Eating Disorders Review, 21(3), 230-237. http://dx.doi.org/ 10.1002/erv.2210 